\title{
LEAF GAS EXCHANGE CHARACTERISTICS OF DROUGHT STRESSED LINDEN (TILIA SP.) TREES
}

\author{
Tóth, E. Gy. ${ }^{1}$ - JUHÁSZ, Á. ${ }^{2}$ - SÜTÖRINÉ DiÓSZEGI, M. ${ }^{1}$ - STEINER, M. ${ }^{1}$ - HROTKÓ, K..$^{*}$ \\ ${ }^{1}$ Corvinus University of Budapest, Department of Floriculture and Dendrology \\ 1118. Villányi út 29-43., Budapest, Hungary \\ (phone: +36-1-482-6271) \\ ${ }^{2}$ Corvinus University of Budapest, Department of Soil Science and Water Management \\ 1118. Villányi út 29-43., Budapest, Hungary \\ (phone: +36-1-482-6273) \\ *Corresponding author \\ e-mail: karoly.hrotko@uni-corvinus.hu
}

(Received $30^{\text {th }}$ Dec 2013; accepted $30^{\text {th }}$ Sept 2014)

\begin{abstract}
The daily course of leaf gas exchange was investigated on six linden cultivars from Tilia cordata Mill., T. platyphyllos Scop., T. tomentosa Moench and T. americana L. After the morning peak rapid stomatal closure was detected on leaves of $T$. cordata 'Savaria', 'Greenspire' and T. platyphyllos 'Favorit'. The stomatal conductance on leaves of $T$. tomentosa 'Szeleste' after the midday drop was significantly higher, while highest was on T. americana 'Redmond' leaves during the whole day. The transpiration resulted significant differences in daily water use (T. cordata 'Savaria' and T. platyphyllos 'Favorit': $1.0 \mathrm{~kg} \cdot \mathrm{m}^{-2} ;$ T. americana 'Redmond', $2.3 \mathrm{~kg} \cdot \mathrm{m}^{-2}$ of leaf area). Due to rapid stomatal closure $T$. cordata and T. platyphyllos cultivars realized water saving on the cost of strongly reduced carbon gain. Corresponding to their drought and heat adaptability the performance of leaves of $T$. tomentosa cultivars showed low level stress symptoms, intermediate level of transpiration and carbon gain. T. americana 'Redmond' leaves transpired largest water quantity, which resulted in large water loss and relatively intense stress symptoms. The large cultivar differences in the performance of leaf gas exchange should be considered at evaluation of drought stress adaptability and environmental benefits $\left(\mathrm{CO}_{2}\right.$ fixation, $\mathrm{O}_{2}$ and vapor release) of Tilia cultivars.
\end{abstract}

Keywords: $\mathrm{CO}_{2}$ assimilation, environmental benefits, transpiration, urban forestry, water use

\section{Introduction}

Linden species (Tilia sp.) represent an important genus in Central Europe (Radoglou et al. 2008) and are widespread planted under urban conditions in form of different cultivars. The following species are commonly planted for urban forestry in Hungary: $T$. cordata Mill. and T. platyphyllos Scop., (native to Europe forming climax forest); $T$. tomentosa Moench, (native to Southern Europe and Asia); T. americana L. (cultivars were introduced recently). Despite of their importance, there is little and inconsistent knowledge on the drought tolerance and leaf gas exchange performance of linden cultivars under urban conditions.

Most of the authors agree on wider adaptability of T. cordata Mill. (Hölscher 2004; Hölscher et al. 2005; Radoglou et al. 2008), while data of Köcher et al. (2009) indicate moderate drought sensitivity. Results of Fini et al. (2009) indicate that T. tomentosa and $T$. cordata are more drought tolerant during establishment than $T$. platyphyllos. Similarly inconsistent data are available on drought tolerance of T. americana (Abrams et al. 1998, Klos et al. 2009, Gustafson and Sturtevant 2012, Gilman and Watson 2012). 
Water stress results in stomatal closure and reduced transpiration rates, decrease in the water potential of plant tissues, and diminish the photosynthesis. Further on higher growth inhibition and accumulation of abscisic acid is caused (Davies and Zhang 1991, Yordanov et al. 2003). Stomatal control of leaf transpiration is considered as short term dynamic adaptation to water stress; the reduced transpiration contributes to avoiding decrease of leaf water potential (Sperry 2000; Bréda et al. 2006). Several investigation showed that stomatal responses are more closely linked to soil moisture content than to leaf water status: stomata are responding to chemical signals (e.g. abscisic acid) produced by dehydrating roots (Davies and Zhang 1991).

High transpiration demand induced by environmental conditions and low soil water content leads to the decrease of the leaf water potential. As a result of this drop, stomatal closure occurs in most tree species, limiting water fluxes at the cost of reduced $\mathrm{CO}_{2}$ assimilation (Sperry et al. 2002; Bréda et al. 2006). Some drought-tolerant species control stomatal function to allow some carbon fixation at stress, thus improving water use efficiency. Higher transpiration rates have been reported for Fraxinus americana in contrast to $T$. cordata. Linden tends to avoid drought by maintaining low transpiration rates and higher water potential, whereas ash tends to tolerate drought sustaining higher transpiration rate despite decreasing water potential. From the standpoint of the selecting urban use, both water balance strategies are successful (Withlow and Bassuk 1988).

The above leaf gas exchange characteristics influence the drought adaptability and some major environmental benefits $\left(\mathrm{CO}_{2}\right.$ fixation, $\mathrm{O}_{2}$ and vapor release) of urban trees. Since there are little and inconsistent data on drought and heat adaptability of linden cultivars we aimed in this work to evaluate the leaf gas exchange, stomatal performance of leaves on different linden taxa under drought stress conditions in order to gain information on the diurnal course of stomatal conductance, $\mathrm{CO}_{2}$ fixation and water use.

\section{Materials and methods}

\section{Site conditions}

The investigations were carried out in Soroksár Station of Experimental Farm of Corvinus University of Budapest. Soroksár station (47³8'LN; 19 14'LE, $103 \mathrm{~m}$ above the sea level) is located in Central Hungary, South-East of Budapest. The yearly average temperature is $11.3{ }^{\circ} \mathrm{C}$, and the total sunshine is 2079 hours. Average annual rainfall is about $550 \mathrm{~mm}$ falling mainly in May and June. The soil type is light sandy, lime content is around $2.5 \%$, soil organic matter is low $(0.8-0.9 \%), \mathrm{pH}$ is 7.7 .

An automatic weather system was installed close to the investigated trees $(\sim 300 \mathrm{~m})$ to measure meteorological variables at 10 minutes interval, recorded by Campbell CR 100 data loggers. Temperature and relative humidity were observed by Vaisala HMP35 in the research station (Fig. 1 and Fig. 2). Precipitation, wind speed and global radiation were also monitored (Fig. 2 and Fig. 3). 2011 was extremely droughty year in Hungary. Since the beginning of the meteorological observation this year was the driest (Weather Report of the Hungarian Meteorological Society, 2012).

The month August is characterized by increasing air temperature and decreasing air humidity (Fig. 1). Further on the low amount of rain measured on the investigated area (total $2.2 \mathrm{~mm}$ precipitation in the whole month of August 2011) increased the drought. In the days of 25-26 August there was hot-wave at the site. The daily maximum temperature $\left(\mathrm{T}_{\max }\right)$ reached the $34.6^{\circ} \mathrm{C}$, along clear sky on both days (Fig. 1 and Fig. 2). 


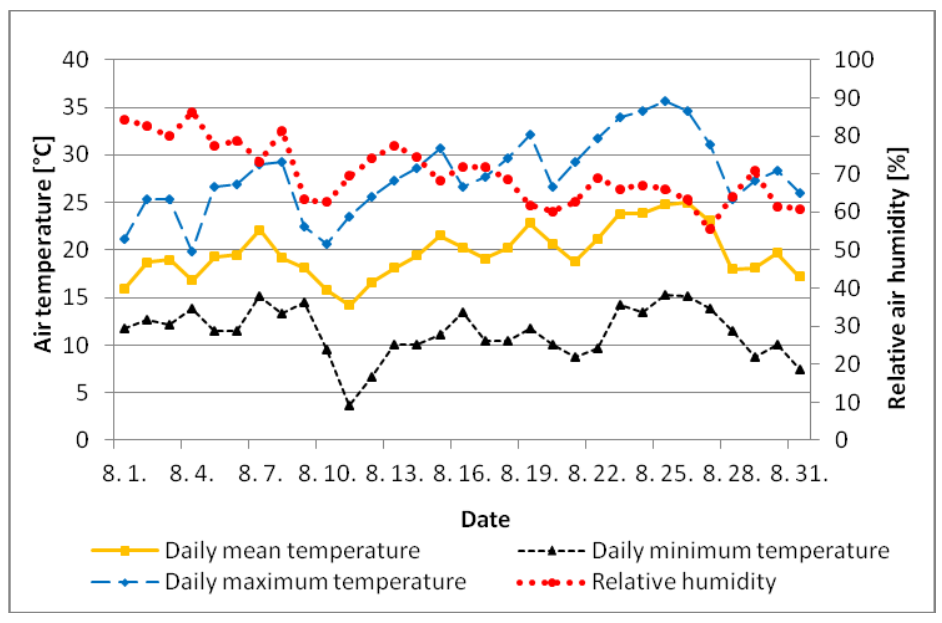

Figure 1. Performance of air temperature and relative air humidity at Soroksár research station in August 2011

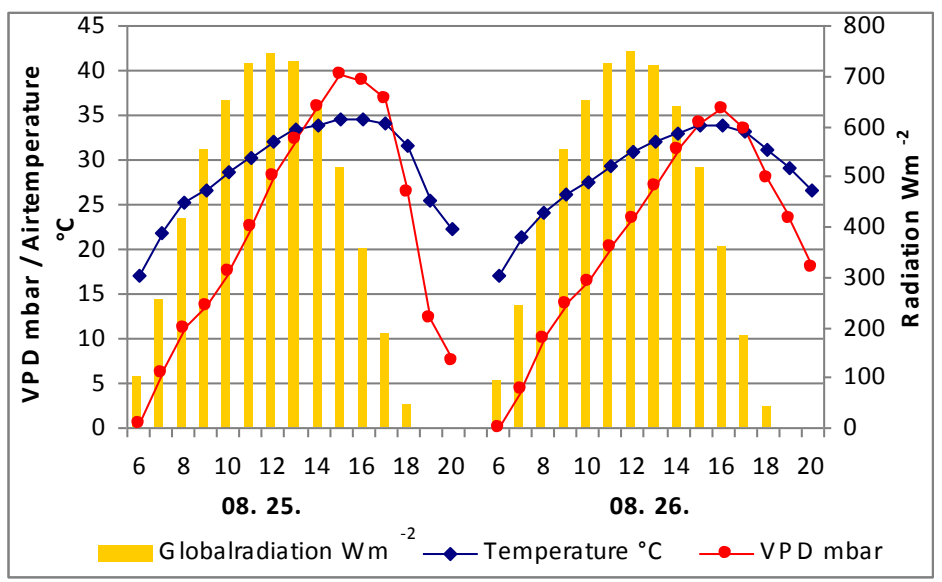

Figure 2. Global radiation, air temperature and vapor pressure deficit (VPD) on the days of investigations in 2011

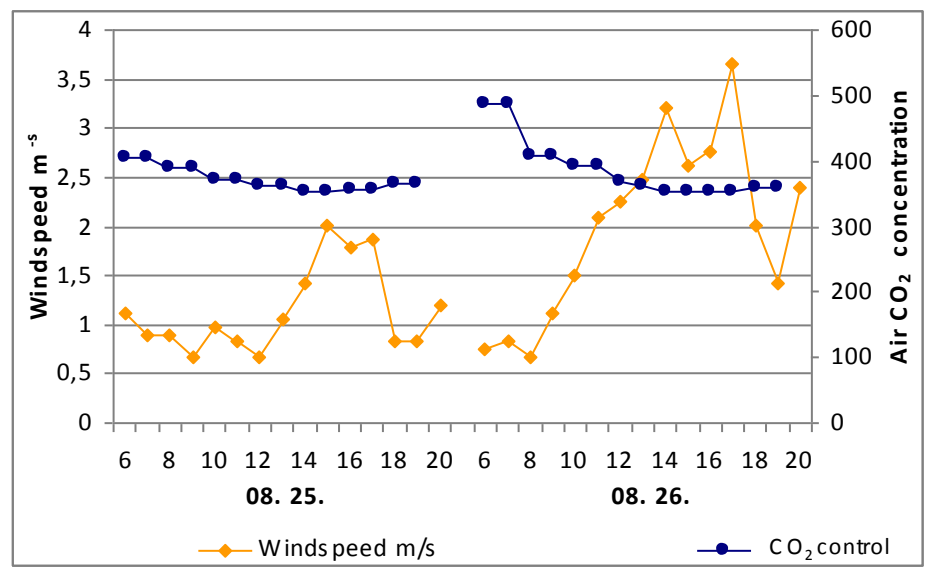

Figure 3. Wind speed and ambient air CO2 concentration on the days of investigations in 2011 
The weather circumstances (high vapor pressure deficit (14 mbar) and global radiation $\left(245-247 \mathrm{~W} \mathrm{~m}^{-2}\right)$ favored the transpiration. Potential evapotranspiration was calculated for $4.0-4.4 \mathrm{~mm}$. The mean relative humidity was $63-66 \%$.

\section{Plant material and methods of leaf gas exchange measurements}

Six linden cultivars propagated by budding, were involved in the trial: Tilia americana 'Redmond', Tilia cordata 'Greenspire', T. c. 'Savaria', Tilia platyphyllos 'Favorit', T. tomentosa 'Szeleste' and T. t. 'Zentai Ezüst'. The investigated linden trees were planted in first week of December 2009, with a trunk circumference 120-140 mm. The trees showed a well developing shape in their establishment stage and overall appropriate horticultural performance (Tóth et al. 2012). The canopies reached $1-1.4$ $\mathrm{m}$ diameter, so the leaves were well illuminated.

The visual symptoms of water and heat stress on the leaves were observed and evaluated by rating, as follows. Rating 0: no symptoms, 1: light wilting of leaves, 2: severe wilting, yellowish or dried patches on leaves up to $25 \%, 3$ : severe wilting, yellowish and dried patches on leaves up to $50 \%$, 4: severe wilting, yellowish and dried patches on leaves up to $75 \%$, leaf fall.

The parameters of leaf gas exchange were investigated by using portable infrared gas analyzer (LCi, ADC BioScientific Ltd, UK). Healthy and well developed trees were chosen to take the measurements; two trees from each cultivars. We measured the leaf gas exchange on four leaves from each tree, possibly with similar PAR exposition, according to the points of the compass, on each side of trees. The measurements were taken in 2011 august 25 and 26, with very similar meteorological characteristics (Fig 1 and 2). The measurements started at 6:30 AM and finished at 7:30 PM. Measurements of one series (four leaves on one tree of the six cultivars) took one hour and were repeated in two hour intervals from 6:30 AM to 7:30 PM. In the first day we measured leaves of one tree of each cultivar, on the other day the same measurements were done on another tree. So in each one-hour-long time interval we collected data from 8 leaves of the same cultivar. Data from eight leaves from the same time intervals of the two days were averaged and statistically analyzed. During the two days, all together 672 leaf data were collected. Further on 2 parameters were calculated; daily (from 6:00 AM to 8:00 PM) accumulated transpiration and $\mathrm{CO}_{2}$ assimilation as product of time and mean values of the time intervals. In calculation of accumulated transpiration and $\mathrm{CO}_{2}$ assimilation each mean value from the one-hour-long measurement's interval was applied for two-hours-long time intervals from 6:00 AM to 8:00 PM, assuming that mean value represents the two-hour-long interval. Data were analyzed with SPSS 2.0, Repeated measures ANOVA and One-way ANOVA were used. Data of species and cultivars were compared to $T$. tomentosa 'Szeleste', which is one of the most widespread planted registered cultivar in Hungary.

\section{Results}

We observed considerable different visible water and heat stress symptoms on leaves of linden cultivars (Table 1). The rating indicates most severe symptoms on T. cordata 'Greenspire' while the leaves of $T$. tomentosa 'Szeleste' showed significant less symptoms. Rating of leaves on all the other cultivars resulted intermediate levels of symptoms without any significant differences related to above two cultivars. 
Table 1. Rating of visible drought stress symptoms on leaves of linden cultivars

\begin{tabular}{l|rl}
\hline Species and cultivar & severity of visible symptoms \\
\hline T. cordata 'Greenspire' & $2.58 \mathrm{~b}$ \\
T. americana 'Redmond' & $1.92 \mathrm{ab}$ \\
T. tomentosa 'Zentai ezüst' & $1.43 \mathrm{ab}$ \\
T. platyphyllos 'Favorit' & $1.25 \mathrm{ab}$ \\
T. cordata 'Savaria' & $1.21 \mathrm{ab}$ \\
T. tomentosa 'Szeleste' & $0.50 \mathrm{a}$ \\
\hline
\end{tabular}

The temperature of measured leaves on different linden cultivars showed in each time interval significant differences (Fig. 4). There are distinct groups of cultivars, where the leaf temperature showed more or less similar performance. The lowest leaf temperature was measured on $T$. americana cultivars, except for the late afternoon hours (16:00 - 20:00). In the next group of Tilia cordata cultivars there are significant differences within the group in the early hours; between 12:00 - 14:00 all the T. cordata cultivars showed similarly mesic leaf temperature. The highest leaf temperature was measured in each time interval on T. tomentosa cultivars, while T. platyphyllos 'Favorit' showed leaf temperature between $T$. cordata and $T$. tomentos $a$ cultivars.

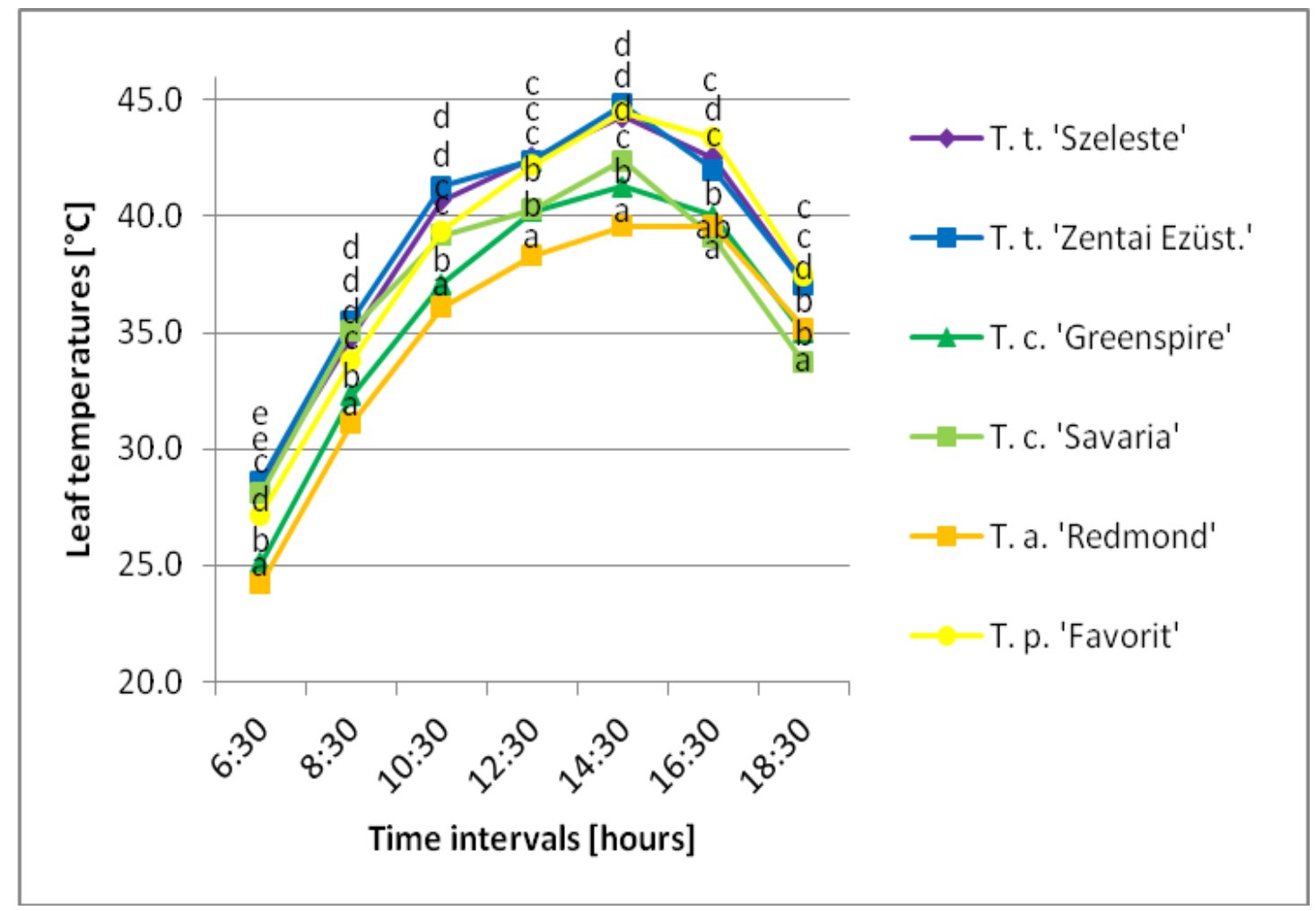

Figure 4. Performance of leaf temperature on linden cultivars

The leaves of linden cultivars showed significant differences in daily cumulated transpiration expressed in $\mathrm{g} \mathrm{m}^{-2}$ of leaf surface (Fig. 5). Leaves of T. americana 'Redmond' $\left(2.3 \mathrm{~kg} \mathrm{~m}^{-2}\right)$ transpired significant more water than the control, while the 
transpiration of leaves on T. tomentosa 'Zentai Ezüst', T. cordata 'Greenspire', 'Savaria', and T. platyphyllos 'Favorit' was significant lower than that of control. With the lowest transpiration the T. cordata 'Savaria' and T. platyphyllos 'Favorit' formed a group with low water use, their cumulated transpiration was about $1.0 \mathrm{~kg} \mathrm{~m}^{-2}$.

The same trend is found on the daily cumulated $\mathrm{CO}_{2}$ assimilation (Fig. 6). The highest assimilation was measured on $T$. americana cultivar, while the lowest on $T$. cordata 'Savaria' and T. platyphyllos 'Favorit' cultivars.

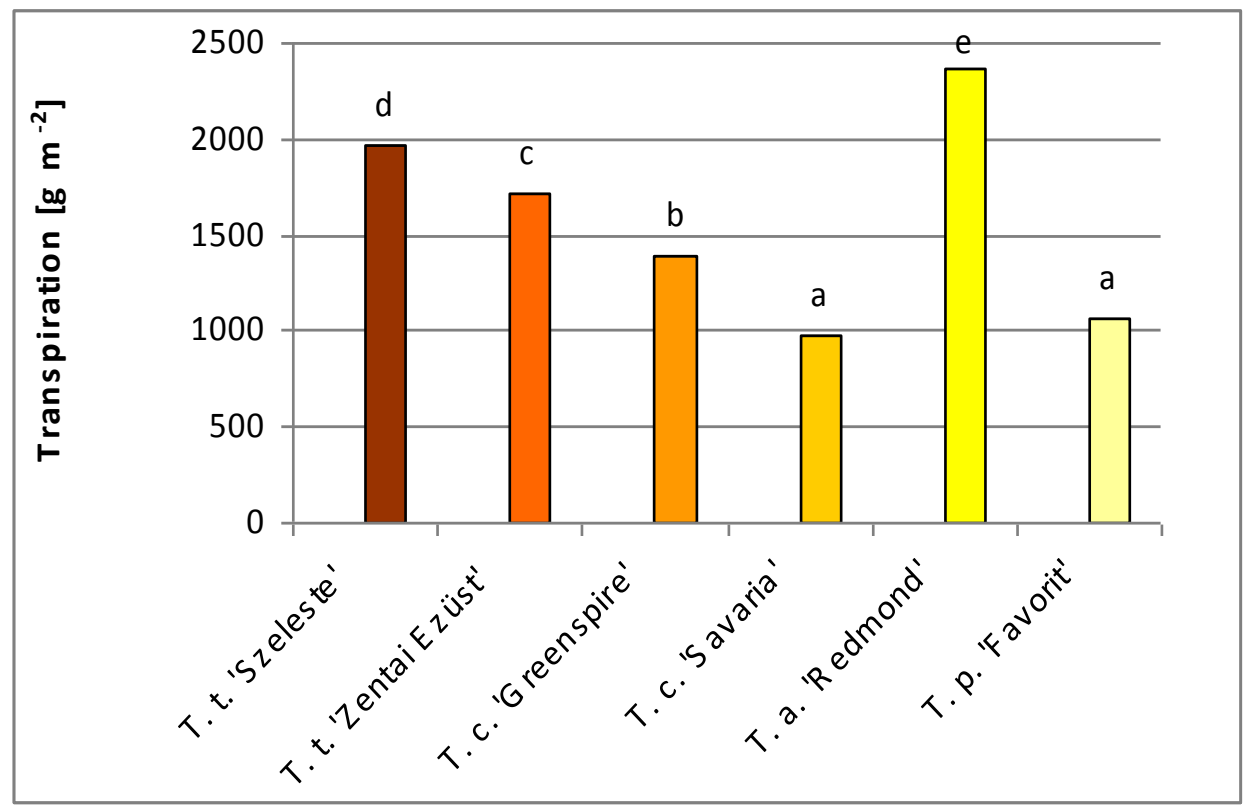

Figure 5. Daily cumulated transpiration of linden leaves $(g \cdot m-2)$

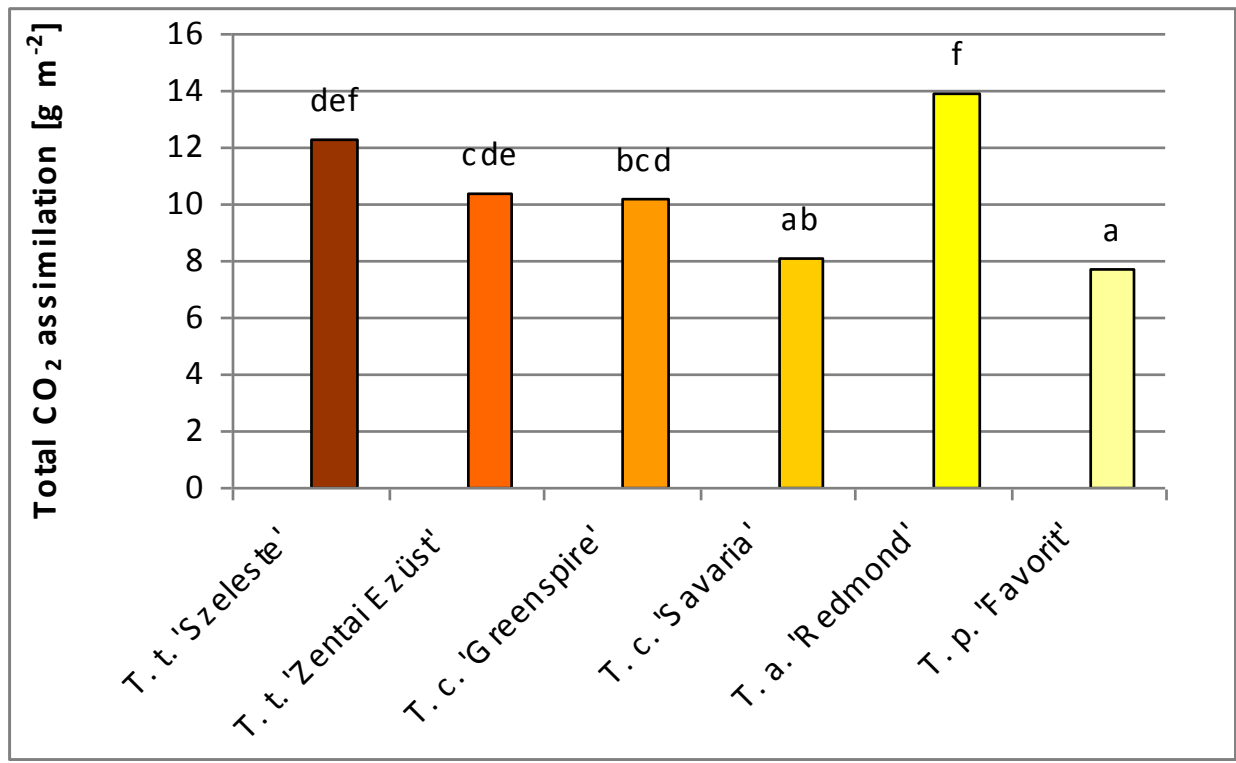

Figure 6. Daily cumulated $\mathrm{CO}_{2}$ assimilation of linden leaves $\left(\mathrm{g} \cdot \mathrm{m}^{-2}\right)$ 


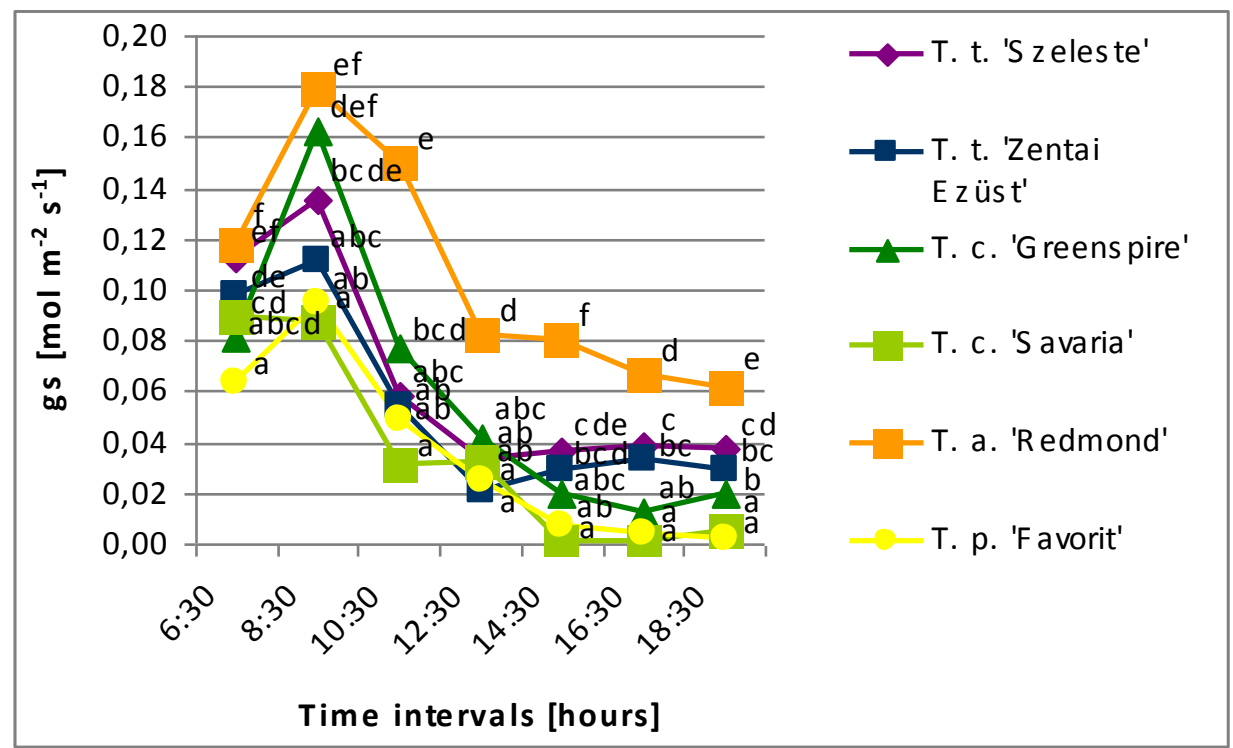

Figure 7. Daily course of stomatal conductance $(\mathrm{gs})$ of linden leaves $\left(\mathrm{mol} \cdot \mathrm{m}^{-2} \cdot \mathrm{s}^{-1}\right)$

The daily course of stomatal conductance $(g s)$ showed a performance typical to drought stressed plants (Fig. 7). The daily maximum was achieved between 8:30 to 9:30, followed by rapid decrease to very low level, but with considerably large cultivar differences. In the early morning (6:30 to 7:30) low stomatal conductance was measured on leaves of $T$. platyphyllos 'Favorit' and on both $T$. cordata cultivars, compared to the control (T. tomentosa 'Szeleste'). In the daily maximum period from 8:30 to 9:30 the stomatal conductance of $T$. cordata 'Savaria' was significant lower, while T. americana 'Redmond' was higher than that of control. In the following sections of the day until 19:30 the stomatal conductance of $T$. americana 'Redmond' leaves remained higher than that of control during the whole day. On the other hand, T. cordata 'Savaria' and $T$. platyphyllos 'Favorit' showed significant lower stomatal conductance in the afternoon period from 14:30 to 19:30 (Fig. 7). By the end of the day, as the global radiation reduced to minimum, similar differences remained between cultivars.

The daily course of transpiration (E) (Fig. 8) on T. cordata and T. platyphyllos leaves showed the peak in the morning hours, between 8:30 to 9:30, than decreased to low level from 12:30 to 18:30, while the midday drop on $T$. tomentosa and T. americana cultivars was followed by a minor peak in the afternoon. Compared to the control $T$. americana 'Redmond' showed higher transpiration between 10:30 to 15:30, and the highest peak between 12:30 to 13:30. Cultivars T. platyphyllos 'Favorit', T. cordata 'Savaria' and 'Greenspire' showed lower transpiration without any second peak. Between 18:30 to 19:30 cultivars T. platyphyllos 'Favorit' and both T. cordata cultivars transpired less than the control T. tomentosa 'Szeleste'.

The daily course of net $\mathrm{CO}_{2}$ assimilation rate $(A)$ of leaves performed similarly to stomatal conductance: the daily maximum was achieved between 8:30 to 9:30, followed by rapid decrease to low level, with considerably large cultivar differences (Fig. 9). In the early morning peak (8:30 to 9:30) highest $\mathrm{CO}_{2}$ assimilation was measured on $T$. cordata 'Greenspire' and T. americana 'Redmond', while T. cordata 'Savaria', and T. tomentosa 'Zentai Ezüst' showed significant lower values. In the early afternoon hours (14:30) all the cultivars produced less $\mathrm{CO}_{2}$ fixation compared to $T$. americana 
'Redmond', while at 16:30 both $T$. tomentosa cultivars recovered, showing higher net $\mathrm{CO}_{2}$ assimilation, than that of T. cordata cultivars and T. platyphyllos 'Favorit'.

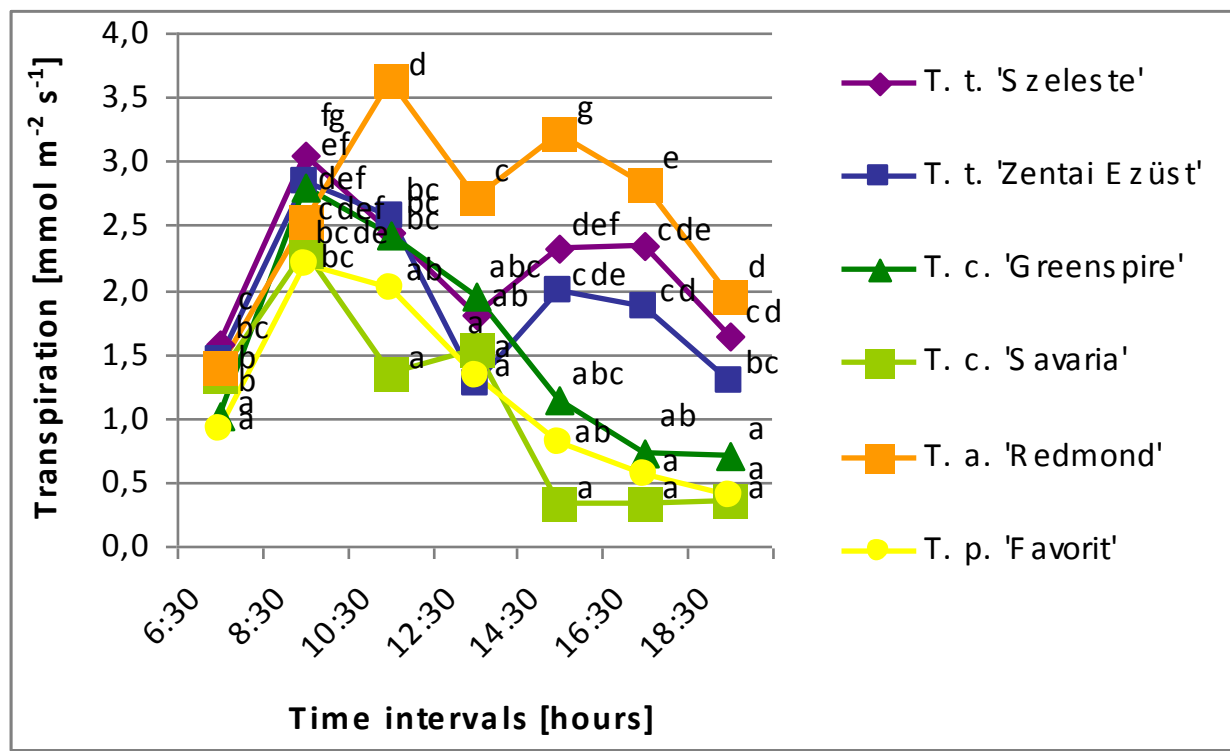

Figure 8. Daily course of transpiration of linden leaves $\left(\mathrm{mmol} \cdot \mathrm{m}^{-2} \cdot \mathrm{s}^{-1}\right)$

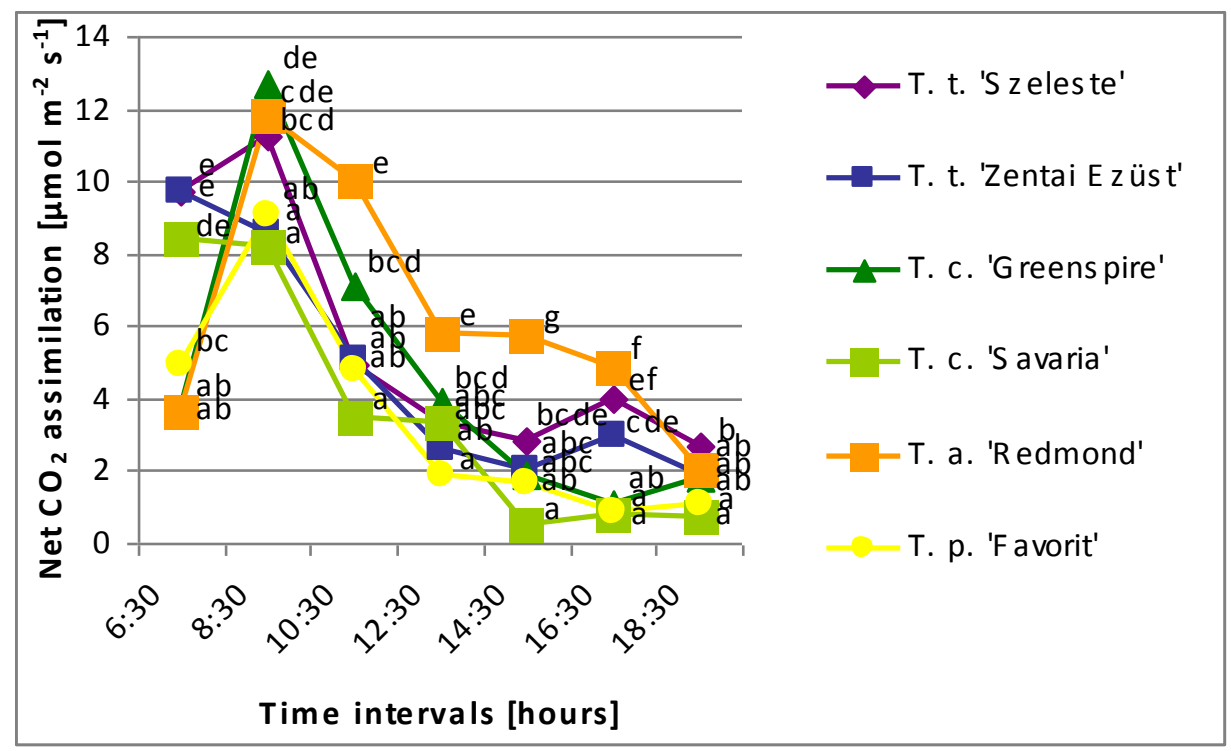

Figure 9. Daily course of net $\mathrm{CO}_{2}$ assimilation of linden leaves $\left(\mu \mathrm{mol} \cdot \mathrm{m}^{-2} \cdot \mathrm{s}^{-1}\right)$

\section{Discussion}

Meteorological data measured in August 2011 and on the days of investigations (Fig. 1, Fig. 2 and Fig. 3) indicate that linden trees in establishing stage (planted in 2009) on light sandy soil were exposed to severe drought. Based on the visible symptoms the leaves of $T$. cordata 'Greenspire' were mostly injured by water stress while $T$. tomentosa 'Szeleste' could be considered as most tolerant (Table 1). This evaluation of 
T. tomentosa is in agreement with Schmidt and Tóth (2006) and Radoglou et al. (2008) while the large injuries on both $T$. cordata cultivars do not confirm their adaptability in the investigated establishing stage.

The leaves showed a diurnal course of stomatal conductance typical to water stressed plants: the daily maximum was around 8:30, than decreased to the minimum. The observed performance of stomatal conductance - corresponding to Withlow and Bassuk (1988) - confirms that the stomatal control is a basic element of water balance strategy of linden cultivars but in this trait the linden (Tilia sp.) species and cultivars performed differently related to the leaf symptoms (Fig. 7). By the stress symptoms most concerned leaves of $T$. cordata 'Greenspire', 'Savaria' and $T$. platyphyllos 'Favorit' showed low level of stomatal conductance during the whole day. This strategy as a short term dynamic adaptation to water stress may efficiently contribute to the water saving (Sperry et al. 2000; Yordanov et al. 2003; Bréda et al., 2006). The largest conductance was measured during the whole day on $T$. americana 'Redmond', which is in correspondence with its daily water use and low leaf temperature (Fig. 4 and Fig. 5). Both T. tomentosa cultivars produced a second minor peak in the afternoon, which is in correspondence to their trends of transpiration. The performance of leaf stomatal conductance indicates considerable differences in short term dynamic adaptability of linden cultivars to water stress that would need further investigation.

The cumulated daily water use does not correspond with the severity of visible water stress symptoms. From among the highly stressed cultivars T. americana 'Redmond' leaves transpired double amount of water related to the similarly stressed $T$. cordata 'Greenspire' and 'Savaria' (Fig. 3). Within T. cordata there are significant differences (Fig. 3) in favor to 'Savaria'. This performance of daily course of transpiration resulted in more than twofold differences daily vapor release: $T$. cordata 'Savaria' and $T$. platyphyllos 'Favorit' leaves transpired around $1.0 \mathrm{~kg} \cdot \mathrm{m}^{-2}$ a day while T. americana leaves consumed $2.3 \mathrm{~kg} \cdot \mathrm{m}^{-2}$.

The transpiration according to the stress symptoms and performance of stomatal control remained on a low level, 0.5 to $3.5 \mathrm{mmol} \cdot \mathrm{m}^{-2} \cdot \mathrm{s}^{-1}$ (Fig. 5). For leaves of $T$. cordata in forest stands of Southern Moravia Kazda et al. (2000) found at light saturation $\left(A_{\max }\right)$ as highest mean transpiration rate $E=3.48 \mathrm{mmol} \cdot \mathrm{m}^{-2} \cdot \mathrm{s}^{-1}$; this is similar value to those that we have measured on leaves of $T$. americana 'Redmond'. To the same time $T$. cordata 'Savaria' transpired $60 \%$ water amount only, and in the afternoon hours the transpiration decreased to $10 \%$. By the daily course of transpiration of leaves cultivars could classified into two groups: both T. cordata and T. platyphyllos after the daily maximum in the morning show a rapidly decreasing trend, while $T$. americana and both $T$. tomentosa cultivars showed a second peak in the afternoon. This performance of the last two species suggests a larger water uptake, reserve or supply capacity in the soil-plant-air complex of these cultivars.

When comparing the transpiration of leaves to the leaf temperature (Fig. 4), we can state that the significant higher transpiration on $T$. americana leaves is more efficient in cooling the leaves during the daytime. From among the T. cordata cultivars we measured highest leaf temperature on 'Savaria' during the daytime, which seems to be in correspondence to its low transpiration capacity, but the low leaf temperature of this cultivar between 16:00 - 20:00 cannot be explained by transpiration activity. It is conspicuous that $T$. tomentosa cultivars with their relatively high transpiration capacity, and late afternoon peak, showed the highest leaf temperature (Fig. 4). 
The above observation suggests considerable cultivar differences in adaptability to water stress conditions. Cultivars of $T$. cordata and T. platyphyllos showed an efficient short term dynamic adaptation to water stress by stomatal control (Sperry 2000; Bréda et al. 2006), while cultivars of $T$. tomentosa and $T$. americana could maintain the transpiration of leaves on a relative higher level and produce a second peak after the midday drop. The low level of visual leaf symptoms by water stress of $T$. tomentosa corresponds to this, but mesic leaf symptoms of $T$. americana are not in line. The high stomatal conductance and transpiration of $T$. americana 'Redmond' leaves support the Gilman and Watson's (2012) statement on drought tolerance of this cultivar but the intermediate level of visual symptoms are in disagreement. Maintaining the steady water status of $T$. americana 'Redmond' leaves requires double amount of water supply.

The daily trend of net $\mathrm{CO}_{2}$ assimilation $(A)$ more or less followed the stomatal conductance; similarly to Forrai et al. (2012) at maximum level we measured 10-14 $\mu \mathrm{mol} \cdot \mathrm{m}^{-2} \cdot \mathrm{s}^{-1}$, which rapidly decreased to $2-6 \mu \mathrm{mol} \cdot \mathrm{m}^{-2} \cdot \mathrm{s}^{-1}$ to the early afternoon hours. Under drought stress the low stomatal conductance strongly controlled the carbon assimilation of Tilia leaves, which resulted significant differences in the daily accumulated carbon gain (Fig 4.). The leaves of T. americana 'Redmond' assimilated maximum quantity $\mathrm{CO}_{2}$ a day, while $T$. cordata 'Savaria' and $T$. platyphyllos 'Favorit' assimilated lowest. This performance of daily cumulated carbon gain suggest that leaves of $T$. americana 'Redmond' can realize their maximum assimilation at higher transpiration costs. On the other hand, the leaves of $T$. cordata 'Savaria' and $T$. platyphyllos 'Favorit' realized water saving on the cost of strongly reduced carbon gain, which confirms Kazda et al. (2000). Corresponding to their drought and heat adaptability (Schmidt and Tóth 2006), in this concern, the performance of leaves of $T$. tomentosa cultivars showed intermediate level of transpiration and carbon gain. This performance was described by Sperry et al. (2002) and Bréda et al. (2006) as traits of tolerant species or cultivars.

The daily cumulated $\mathrm{CO}_{2}$ assimilation of leaves was highest on $T$. americana 'Redmond', which is in correspondence with their largest stomatal aperture, transpiration and lower leaf temperature. In contrary, all the T. tomentosa cultivars with low stomatal aperture but large transpiration capacity showed the highest leaf temperature. Despite of the highest leaf temperature their leaves produced medium level of cumulated $\mathrm{CO}_{2}$ assimilation. This suggests a larger heat tolerance of this cultivars. Within the T. cordata cultivars the large differences in transpiration and cumulated $\mathrm{CO}_{2}$ assimilation indicates that the water saving cultivar 'Savaria' realizes this on cost of assimilation capacity.

\section{Conclusion}

Although the leaf transpiration alone is not an appropriate indicator of drought tolerance of linden cultivars, the differences between cultivars in leaf gas exchange characteristics suggest need on further investigations. The performance of $T$. tomentosa and $T$. americana indicate that in the soil-plant-air complex of these species there might be a more efficient mechanism in water uptake or larger water reservation and supply capacity, which allows maintaining the higher level of transpiration. However, we are aware of that leaf physiology, alone, is not a good predictor of the whole plant responses to drought (Sperry 2000, Yordanov et al. 2003, Bréda et al., 2006), the above performance of stomatal control and transpiration of leaves on Tilia cultivars should be 
considered in cultivar evaluation for urban forestry. The above leaf gas exchange characteristics strongly influence the drought adaptability, ornamental value and the environmental benefits $\left(\mathrm{CO}_{2}\right.$ fixation, $\mathrm{O}_{2}$ and vapor release) of the investigated Tilia cultivars under stress conditions.

Acknowledgements. The authors acknowledge the support from the National Scientific Grants TÁMOP4-2.1.B-09/1/KMR- 2010-0005, and by Hungarian Scientific Research Funds OTKA 109361.

\section{REFERENCES}

[1] Abrams, M.D., Ruffner, C.M., Morgan, T.A. (1998): Tree ring responses to drought across species and contrasting sites in the ridge and valley of Central Pennnsylvania. Forest Sci. 44.4: 550-558.

[2] Bréda, N., Huc, R., Granier, A., Dreyer E. (2006): Temperate forest trees and stands under severe drought: a review of ecophysiological responses, adaptation processes and long-term consequences Ann. For. Sci. 63:625-644.

[3] Davies, W.J., Zhang, J. (1991): Root Signals and the Regulation of Growth and Development of Plants in Drying Soil. Annual Review of Plant Physiology and Plant Molecular Biology 42:55-76.

[4] Fini, A., Ferrini, F., Frangi, P., Amoroso, G., Piatti R. (2009): Withholding Irrigation During the Establishment Phase Affected Growth and Physiology of Norway Maple (Acer platanoides) and Linden (Tilia spp.). Arboriculture \& Urban Forestry 35:241-251.

[5] Forrai, M., Diószegi, S. M., Ladányi, M., Honfi, P. and Hrotkó, K. (2012): Studies on estimation of leaf gas exchange of ornamental woody plant species. Applied Ecology and Environmental Research, 10(2): 195-206.

[6] Gilman. E.F., Watson, D.G. (2012): Tilia americana 'Redmond': 'Redmond' American Linden. University of Florida, IFAS Extension ENH 793.

[7] Gustafson, E.J., Sturtevant, B.R. (2012): Modeling Forest Mortality Caused by Drought Stress: Implications for Climate Change. Ecosystems DOI: 10.1007/s10021-012-9596-1 Springer Springer Science+Business Media

[8] Hölscher, D. (2004): Leaf traits and photosynthetic parameters of saplings and adult trees of co-existing species in a temperate broad-leaved forest. Basic and Applied Ecology 5: 163-172.

[9] Hölscher, D., Koch, O., Korn, S., Leuschner, Ch. (2005): Sap flux of five co-occurring tree species in a temperate broad-leaved forest during seasonal soil drought. Trees 19:628-637.

[10] Kazda, M., Salzer, J., Reiter, I. (2000): Photosynthetic capacity in relation to nitrogen in the canopy of a Quercus robur, Fraxinus angustifolia and Tilia cordata flood plain forest. Tree Physiology 20:1029-1037.

[11] Klos, R.J., Wang, G.G., Bauerle, W.L., Rieck, J.R. (2009): Drought impact on forest growth and mortality in the southeast USA: an analysis using Forest Health and Monitoring data. Ecological Applications 19:699-708.

[12] Köcher, P., Gebauer, T., Horna, V., Leuschner, C. (2009): Leaf water status and stem xylem flux in relation to soil drought in five temperate broad-leaved tree species with contrasting water use strategies. Ann. For. Sci. 66.101. DOI: 10.1051/forest/2008076.

[13] Radoglou, K., Dobrowolska, D., Spyroglou, G., Nicolescu, V.N. (2008): A review on the ecology and silviculture of limes (Tilia cordata Mill., Tilia platyphyllos Scop. and Tilia tomentosa Moench.) in Europe. 29 pp. http://www.valbro.uni-freiburg.de/

[14] Schmidt, G., Tóth, I. (2006): Kertészeti dendrológia (Horticultural Dendrology). Mezőgazda Kiadó, Budapest. 404 pp. 
[15] Sperry, J.S. (2000): Hydraulic constraints on plant gas exchange. Agricultural and Forest Meteorology 2831:1-11.

[16] Sperry, J.S., Hacke, U.G., Oren, R., Comstock, J.P. (2002): Water deficits and hydraulic limits to leaf water supply. Plant, Cell and Environment 25:251-263.

[17] Tóth, E.G., Diószegi, M., Hrotkó, K. (2012): Hungarian and foreign linden varieties' phenological evaluation. Dendrological Days in Mlinany Arboretum SAS 2012. Proceedings of Abstracts. ISBN 978-80-971113-0-4. Page 83.

[18] Weather Report of the Hungarian Meteorological Society. http://www.met.hu/eghajlat/magyarorszag_eghajlata/eghajlati_visszatekinto/elmult_evek _idojarasa/ (2 March 2013, date last accessed)

[19] Withlow, T.H., Bassuk, N.L. (1988): Urban Trees Ecophysiology and Their Management - The North American Experience. HortScience, 23:542-546.

[20] Yordanov, I., Velikova, V., Tsonev, T. (2003): Plant responses to drought and stress tolerance. Bulg. J. Plant Physiol. Special Issue, 187-206. 